\title{
Implementation research methods: an extension tool in health education and information
}

\begin{abstract}
Mozambique has high maternal and new-born mortality rates. The Alert Community for a Prepared Hospital care continuum project is an implementation research, aiming to reduce maternal and new-born mortality rates in Natikiri, Nampula, and Northern Mozambique. Target groups (women, adolescents, heads of families, religious leaders, community leaders, traditional midwives, counsellors of initiation rites, traditional healers, secondary school pupils and teachers) were submitted to repeated intermediate evaluations (surveys, interviews and focus groups discussions), improving knowledge, attitude and practice on sexual and reproductive health and rights and family planning. Implementation research methods were an efficient extension tool in population health education and health and educational professionals vocational training.
\end{abstract}

Keywords: behaviour change, data collection, health education, implementation research, Mozambique, research methods
Volume 4 Issue 2 - 2020

Paulo Henrique das Neves Martins Pires

Faculty of Health Sciences, Lúrio University, Mozambique

Correspondence: Paulo Henrique das Neves Martins Pires, Faculty of Health Sciences, Lúrio University, Bairro de Marrere, Rua Nr. 4250, km 2.3, Nampula, Mozambique, Tel +258 824235287, Email druiatom@gmail.com

Received: January 23, 2020 | Published: March 17, 2020
Abbreviations: FHS, faculty of health sciences; FP, family planning; $\mathrm{MGH}$, marrere general hospital; $\mathrm{MHC}$, marrere health centre; NAP, natikiri administrative post; SRH, sexual and reproductive health; ULU, unilúrio - lúrio university

\section{Introduction}

Mozambique has high maternal (451.6 maternal deaths per 100,000 live births in 2017) and new-born mortality rates. ${ }^{1}$ The Alert Community for a Prepared Hospital care continuum, is a project promoted by the Faculty of Health Sciences (FHS) of UniLúrio (Lúrio University) in Nampula, Northern Mozambique and the University of Saskatchewan (Canada), in partnership with Nampula Provincial Health Directorate, the Marrere Health Centre (MHC) and the Marrere General Hospital (MGH), the Natikiri Administrative Post (NAP) and other non-governmental organizations with health sector activities in Nampula. This is an implementation research aiming to reduce maternal and neonatal mortality. The activities had three target audiences, namely the population of Natikiri (peri urban area, emacua linguistic ethical group, low level of education and scarce economic resources), health professionals from the MHC and MGH and policy makers in the health sector (at local, provincial and national levels).

\section{Main body}

\section{Intervention}

The interventions took place from 2016 to 2020 . We started with a baseline study, with wide participation of target groups, to identify the causes of the problems under study (maternal and neonatal high mortality rates) and possible solutions. This approach allowed the design of 7 strategies and 20 objectives, to be achieved with 80 different targets. ${ }^{2}$ The implementation research method involves scheduled and repeated intermediate evaluations, with data collection through surveys, interviews and focus groups discussions, taking place in health units, at the university campus, at secondary schools, at family houses and other public facilities. By complying with the ethical guidelines of the Helsinki Declaration, participants receive detailed information about the project (vocal explanation, written information sheet to the participant, answers to personal questions), understand the objectives and methods (informed consent form), presenting doubts and comments to respondents and interviewers at the end of data collection. Data collection were applied by FHS medical, nursing and pharmacy students and by masters in Mother and Child Health, in Portuguese (Mozambican official language) or in Macua (local language), as preferred by the subject.

\section{Impact}

We know that in some cases of research the observer changes the observed, introducing a data collection bias; in our case, this is one of the objectives, improving the knowledge, attitude and practice of the NAP population on sexual and reproductive health (SRH) and rights, contraception, family planning (FP), maternal and children health, health prevention and health services quality. ${ }^{3}$ This objective can be achieved by transferring knowledge from surveyors, interviewers and researchers to target groups.

In the case of the NAP population, the participation of a large and diverse number of people (women, adolescents, heads of families, religious leaders, community leaders, traditional midwives, counsellors of initiation rites, traditional healers, secondary school pupils and teachers, health professionals, health committees members), in various data collection activities, has allowed the dissemination of health information and education: for many participants, it is a first occasion to talk openly about "culturally" sensitive issues rarely discussed in the families and communities, to be considered and listened to as to their opinions on the health problems and services and to clarify doubts in a more "modern and scientific" way. On the other hand, the collection of data carried out by FHS students has 
allowed their specific training in quantitative and qualitative research, reinforcing their knowledge in SRH and FP and on the social and cultural reality of the Mozambican Macua population. Finally, the team of teachers and researchers has been strengthening their ability to study health problems, to design research protocols, innovating solutions and discovering new areas of research and intervention.

\section{Conclusion}

We consider that the data collection methods used in this implementation research, can be an efficient extension tool in population health education, and health and education professionals vocational training.

\section{Acknowledgments}

Iyara Mongo, Delmar Mutereda, Asimbawe Kiza and members of Lúrio University Students Researchers group: Abraão João, Alvido Muaviraca, Bondy Lourenço, Chabuca António, Felizardo Cabral, Jeremias Moquito, Magaios Hassani, Ngulwe Saide, Rainer Araibo, Rossan Benjamim, Zubair Salamo.

\section{Conflicts of interest}

The author declares he has no conflicts of interest with study design or final report, no financial or personal relationships with other people or organizations that could inappropriately influence this research.

\section{Funding}

None.

\section{References}

1. INE. Resultados definitivos censo 2017. Instituto Nacional de Estatística. República de Moçambique. Maputo. 2019.

2. C Belo, P Pires, J Josaphat, et al. Maternal and new-born mortality: community opinions on why pregnant women and new-borns are dying in Natikiri, Mozambique. International Journal of Research. 2017;4(6):119.

3. Pires P, Siemens R, Mupueleque M. Improving sexual and reproductive health and practice in Mozambican families with media campaign and volunteer Family Health Champions. Fam Med Com Health 2019;7(4):e000089. 